\title{
Mudanças climáticas: efeitos sociais sobre povos e comunidades tradicionais da Amazônia
}

\section{Climate change: social effects on people and traditional communities in the Amazon}

Thereza Cristina Cardoso Menezes - Doutora em Antropologia Social pelo Programa de PósGraduação em Antropologia Social do Museu Nacional (UFRJ). Professora do Programa de Pós-Graduação de Ciências Sociais em Desenvolvimento e Agricultura (CPDA/ UFRRJ) e do Programa de Pós-Graduação em Antropologia Social - PPGAS/UFAM. E-mail: therezaccm@uol.com.br

Ana Carla dos Santos Bruno - Doutorado em Antropologia e Lingüística - University of Arizona. Pesquisadora do Instituto Nacional de Pesquisas da Amazônia na Coordenação de Sociedade, Ambiente e Saúde (CSAS/INPA) e Professora do Programa de PósGraduação em Antropologia Social - PPGAS/UFAM. E-mail: abruno@inpa.gov.br

\section{Resumo}

Este artigo busca examinar como as discussões sobre mudanças climáticas estão influenciando práticas sociais de povos e comunidades tradicionais que vivem em Terras Indígenas e Unidades de Conservação situadas na Amazônia, tendo como foco as práticas e os efeitos sociais das políticas públicas para mitigação de riscos ambientais sobre povos indígenas e tradicionais, bem como a incorporação da temática das mudanças climáticas nas agendas dos movimentos sociais que atuam na região. $\mathrm{E}$ por fim, como esta questão tem se traduzido em táticas diversas promovidas por organizações estatais e não governamentais dirigidas para políticas de regularização fundiária na Amazônia.

\section{Palavras-chave}

Risco. Recursos Florestais. Política de Mudanças Climáticas. Indígenas e Povos Tradicionais na Amazônia. Impactos Socioculturais. Políticas de Regularização Fundiária.

\begin{abstract}
This article seeks to examine how climate change discussions are influencing social practices of traditional peoples and communities living in indigenous lands and protected areas located in the Amazon, focusing on the practical and social effects of public policies to mitigate environmental risks on indigenous and traditional peoples, as well as incorporating the theme of climate change on the agendas of social movements operating in the region. And finally, as this question has translated into various tactics promoted by state and non-governmental organizations directed to policies of land regularization in the Amazon.
\end{abstract}

\section{Keywords}

Risk. Forest Resources. Climate Changes Policy. Indigenous and Traditional People in Amazonia. Socio-cultural Impacts. Policies of Land Regularization. 


\section{INTRODUÇÃO}

Este artigo busca refletir sobre as discussões e as práticas motivadas pela intervenção no panorama das chamadas mudanças climáticas. Propomos analisar o processo de transformação na Amazônia das intervenções motivadas pela questão e como estas estão influenciando povos e comunidades tradicionais que vivem em Terras Indígenas, assentamentos sustentáveis e Unidades de Conservação situadas na Amazônia, examinando-se como esta questão tem se traduzido cada vez mais em táticas diversas promovidas por organizações estatais e não governamentais dirigidas para políticas de regularização fundiária. Buscamos ainda analisar como os movimentos sociais se posicionam ou foram incorporados no debate desta temática na Região Amazônica.

As discussões sobre mudanças climáticas tornaram-se um dos tópicos de maior destaque na agenda do século XXI. As causas, os culpados, os riscos e perigos são temas recorrentes não só no universo científico e jornalístico, mas também passaram a fazer parte das agendas dos movimentos sociais e das políticas territoriais dirigidas para a Amazônia. Cabe ressaltar que ainda que a hegemonia discursiva sobre o tema das mudanças climáticas caiba ao mundo científico, observamos por parte dos sujeitos sociais que vivem e relacionam-se intensa e cotidianamente com a Floresta Amazônica, leituras próprias sobre a crescente imprevisibilidade do ritmo de chuvas, cheias, vazantes, bem como sua própria vulnerabilidade diante de tais mudanças.

A proposta deste texto é apontar alguns dos efeitos sociais ancorados na difusão do risco planetário acarretado pelas mudanças climáticas e como a Amazônia deveria converter-se no epicentro de intervenções para minimizálo. Esta perspectiva está hoje materializada em um conjunto muito diverso de políticas públicas que têm entre suas metas fundamentais a redução do índice de desmatamento anual na Amazônia em até $80 \%$ até $2020^{1}$. As ações voltadas para atingir esta meta têm provocado mudanças de grande envergadura no marco legal, assim como produziram novas funções de gestão, vigilância e proteção territorial a serem promovidas por povos e comunidades tradicionais na Amazônia.

Nos últimos anos, inúmeros cientistas difundiram a ideia de que as mudanças climáticas são oriundas de ações humanas inadequadas. Em 1992, na convenção-quadro realizada na Cúpula da Terra no Rio de Janeiro, a chamada ECO 92, discutia-se a necessidade de estabilizar a composição atmosférica para impedir a influência antropogênica no sistema climático sem provocar uma

1 Decreto n $7390 / 2010 /$ Plano de Ação para Prevenção e Controle do Desmatamento na Amazônia Legal (PPCDAm) 
ruptura na economia global. E os discursos, enfaticamente, situavam como causa fundamental da emissão de grande quantidade de gás na atmosfera a retirada de carbono em excesso, principalmente do subsolo (uso de combustíveis fósseis) e das florestas tropicais em ações de desmatamento, tais como na preparação de roçados e atividades agropecuárias e madeireiras.

Segundo o relatório do Intergovernmental Panel on Climate Change (IPCC) 2007, este aquecimento seria diferenciado, pois todo planeta manifestaria seus efeitos: a) Degelo nas calotas polares; b) Mudanças nas dinâmicas e regime das chuvas, o que afeta diretamente a agricultura e o extrativismo; c) Mais ondas de calor e de frio; d) Tempestades e secas mais severas. O relatório pontuava ainda que um aumento da temperatura superior à faixa entre $2,0^{\circ} \mathrm{C}$ e $2,4^{\circ} \mathrm{C}$ seria catastrófico, teríamos uma diminuição substancial da produção agrícola mundial, milhões de refugiados ambientais, milhões de pessoas sofreriam com recorrentes e crescentes falta de água e a biodiversidade da Floresta Amazônica estaria seriamente comprometida.

Segundo Fearnside (2012), toda discussão sobre mudanças climáticas, inclusive os informes do IPCC, alertam para a probabilidade de que os problemas e os riscos sejam maiores do que os estimados. A existência do próprio fato e do seu potencial de gravidade está longe de conformar um consenso no campo científico, existindo profundos embates a respeito dos métodos e questionamentos sobre dados negligenciados em pesquisas, conclusões e estimativas futuras sobre as mudanças climáticas.

No caso da particular da Amazônia, a desertificação das florestas tem merecido grande destaque como um dos mais notórios efeitos das mudanças climáticas. Pesquisas realizadas pela NASA sobre os efeitos de duas das maiores secas já ocorridas na região em 2005 e 2010 demonstraram que estes fenômenos provocaram uma mudança representativa na paisagem. Após as secas, a floresta perderia sua capacidade de absorção de gás carbônico, o que contribuiria para o aquecimento global, formando um ciclo vicioso. Diferentemente das pesquisas que apontam o desmatamento como o principal inimigo da Floresta Amazônica, estas pesquisas indicam que as emissões de gases do efeito estufa mereceriam maior atenção.

Contrariando estas conclusões, os cientistas da Grã-Bretanha sugerem que a Floresta Amazônica pode ser menos vulnerável às secas graves decorrentes do aquecimento global do que se acreditava. Em artigo publicado na revista Proceedings of the National Academy of Sciences, a partir de pesquisas coordenadas por Yavinder Malhi, professor da Universidade Oxford, os cientistas pela primeira vez compararam simulações de Modelos Climáticos 
Globais com observações empíricas e concluíram que muitos dos modelos climáticos subestimam a quantidade atual de chuvas na Amazônia. Previu-se que a parte oriental da Amazônia, úmida durante o ano todo, teria a tendência de se transformar em "florestas sazonais", com estações secas e estações úmidas, mas sem o risco de savanização, visto que estas florestas seriam resistentes a secas ocasionais. Este estudo contraria as projeções do Painel do Clima da ONU que indicavam que a porção oriental da Amazônia poderia ser gradualmente transformada em savana. A pesquisa conclui que a melhor maneira de reduzir o risco de degradação da Amazônia seria o controle das emissões globais de gases do efeito estufa e a proteção da floresta, visto que se estima que o desmatamento pode ser responsável por cerca de $20 \%$ das emissões anuais.

Uma publicação da Nature (2012) baseada no Programa de Grande Escala da Atmosfera-Biosfera da Amazônia (LBA), indica a interdependência de fatores, humanos e naturais pressionando a borda oriental da floresta, nos estados do Pará, do Tocantins e de Mato Grosso. Mesmo considerando a capacidade de recuperação da floresta, a pressão humana proveniente da região de limite com o cerrado iniciaria o processo de savanização.

Diferentemente das previsões pessimistas sobre o impacto do aquecimento global sobre o bioma amazônico, Azis Ab'Saber (2007) foi enfático ao afirmar no Correio Brasiliense que: "É, completamente, errado afirmar que o aquecimento global ocasionará desertificação, savanização ou interrupção natural das florestas|". Segundo o autor, a Floresta Amazônica poderia mesmo tornarse ainda mais densa nos próximos anos, em virtude do aquecimento global que permitiria aumento das temperaturas médias intensificação das precipitações. Apesar de considerar o relatório do IPCC como uma ferramenta relevante de alerta, Ab 'Saber percebe como um sério erro do documento o fato deste desconsiderar a influência das correntes marítimas no clima.

\section{DESMATAMENTO E MUDANÇAS CLIMÁTICAS}

Como tentamos descrever muito brevemente, não há unanimidade sobre a incidência ou risco futuro de savanização da Amazônia. No entanto, boa parte dos estudos recomenda vivamente que se tomem medidas mais efetivas para proteger o ecossistema da ação predatória do homem, visto que no Brasil o desmatamento é a principal fonte de emissões de gases do efeito estufa. Na região onde a fronteira agrícola avança em direção à floresta concentram-se os maiores índices de desmatamento. Entre agosto de 2014 a julho de 2015, percebeu-se uma inflexão, o Brasil perdeu $5.831 \mathrm{~km}^{2}$ de florestas - um aumento de $16 \% \mathrm{em}$ 
relação ao período anterior, segundo o Instituto Nacional de Pesquisas Espaciais (INPE). O Pará e o Mato Grosso lideraram em área total desmatada, porém Amazonas, Rondônia e Mato Grosso tiveram os maiores aumentos em relação ao ano anterior $(54 \%, 41 \%$ e $40 \%)$, respectivamente.

A expansão da pecuária foi a causa principal do desmatamento, seguida do corte seletivo. Dentre as novidades, em relação aos anos mais recentes, notouse o desmatamento em grandes áreas, algo considerado incomum há cerca de uma década e a concentração e o desmatamento em estados que captaram recursos do Fundo Amazônia ${ }^{2}$ para reduzir o desmatamento. Desde meados de 2017, o Fórum das Entidades Empresariais do Pará encaminhou uma carta ao presidente Michel Temer pedindo a suspensão do Fundo Amazônia justificada pela suposta obstrução que a entidade representaria aos setores produtivos do Pará e da Amazônia como um todo. Para estes setores, as organizações não governamentais prejudicariam o desenvolvimento de comunidades do interior além de impor uma tutela não solicitada.

As posturas assinaladas acima colocariam em risco um conjunto de ações em curso nos últimos anos em relação à redução do desmatamento na Amazônia. Tanto a sociedade organizada quanto o Estado se empenharam para que o desmatamento caísse da casa dos $27 \mathrm{mil} \mathrm{km}^{2}$, em 2004, para a faixa dos 5 mil, ainda que o governo federal pouco tenha se empenhado na demarcação de novas Unidades de Conservação e Terras Indígenas. Ao contrário, mudanças severas no marco legal constituem sérias ameaças para biodiversidade e sociodiversidade amazônica, como, por exemplo, a PEC $2015^{3}$, Mudanças no Código Florestal ${ }^{4}$ e

2 O Fundo Amazônia financia ações de redução do desmatamento em biomas brasileiros desde 2008. A Noruega é o maior financiador do Fundo. O Fundo Amazônia tem por finalidade captar doações para investimentos não reembolsáveis em ações de prevenção, monitoramento e combate ao desmatamento, e de promoção da conservação e do uso sustentável da Amazônia Legal. Também apoia o desenvolvimento de sistemas de monitoramento e controle do desmatamento em outros países tropicais (Disponível em: http://www.fundoamazonia.gov. $\mathrm{br} / \mathrm{pt} /$ home/)

3 Proposta de emenda constitucional que delega ao Congresso Nacional o direito de demarcação de Terras Indígenas e Quilombolas

4 Dentre as mudanças no Código Florestal destacaria: a possibilidade de redução da reserva para $50 \%$ de reserva legal em estados com mais de $65 \%$ das suas áreas em reservas ambientais, desde que a redução seja autorizada pelo Conselho Nacional do Meio Ambiente. $\mathrm{O}$ novo texto também assegura a todas as propriedades rurais a manutenção de atividades agrossilvopastoris nas margens dos rios, desde que consolidadas até 2008, e autoriza o uso de áreas de Preservação Permanente para alguns tipos de cultivos, como maçã e café. A pecuária também ficaria permitida em encostas de até 45 grau. Agricultores com propriedade de até 4 módulos fiscais, autuados até julho de 2008, poderiam converter multas com reflorestamento, de acordo com o texto aprovado pela Câmara e estes benefícios valeriam também para os grandes proprietários rurais que desmataram até julho de 2008. Criou-se o Cadastro Ambiental Rural (CAR) autodeclaratório e realizado virtualmente que estabelece prazo para que os donos de terras registrem suas propriedades nesse cadastro. $\mathrm{O}$ cadastro servirá para armazenar informações ambientais de todas as propriedades rurais. Essa base de dados servirá para 
a Lei n⿳⺈ 11.977/09 (antes MP 759) ${ }^{5}$, entre outras.

O aumento do desmatamento costuma associar-se ao crescimento da violência na floresta. O sul do Amazonas e norte de Rondônia tem sido apontados pela Comissão Pastoral da Terra (CPT) como regiões críticas em termos de aumento da escalada na violência no campo, em decorrência dos fatores levantados acima referentes às expectativas da flexibilização legal que prometem crescimento de rebanhos, regularização fundiária desburocratizada e menor fiscalização da exploração madeireira. Dos cem municípios com maiores índices de desmatamento, 61 estão entre os que apresentam as maiores taxas de assassinatos no país, segundo levantamento realizado pela Agência Brasil, que cruzou dados do Prodes - Monitoramento da Floresta Amazônica Brasileira por Satélite com o Mapa da Violência dos Municípios Brasileiros ${ }^{6}$.

Cerca de 500 mil km² de terras que vão do leste e sul do Pará em direção oeste, passando por Mato Grosso, Rondônia e Acre compõem o chamado arco do desmatamento da Amazônia. A faixa territorial que compreende o sul do Amazonas vem se consolidando como nova área de expansão da fronteira agropecuária. Os municípios de Canutama, Lábrea Manicoré, Boca do Acre, Apuí e Humaitá concentram as maiores áreas desmatadas em função da exploração de madeira ilegal e para a criação de novas áreas de pastagens.

A análise de dados recentes de sensoriamento remoto demonstra que as Unidades de Conservação e as Terras Indígenas têm desempenhado um papel fundamental na conservação de extensas áreas contíguas de floresta, em alguns casos em áreas de expansão acelerada de frentes agropecuárias e madeireiras. No entanto, na ausência de ações efetivas para a criação de novas áreas protegidas tornam aquelas que já existem como prioritárias para a conservação e em algumas delas percebe-se um esforço em promover a utilização sustentável visando a repartição dos benefícios da biodiversidade e de outros serviços ambientais. Com este objetivo, houve nos últimos anos um grande esforço do Estado e das organizações não governamentais em promover a proteção territorial e dos recursos ambientais naturais nestes territórios por meio de ferramentas de etnomapeamentos, etnozoneamento, planos de uso e de vida, incentivo

controle, monitoramento, planejamento ambiental e econômico e combate ao desmatamento. O cadastro permite pleitear créditos agrícolas.

5 O Poder Executivo federal editou a Medida Provisória n 759, de 22 de dezembro de 2016, que expressamente revogou os dispositivos daquele diploma afetos ao assunto, trazendo, também, nova disciplina da regularização fundiária rural, da liquidação de créditos concedidos aos assentados da reforma agrária e de mecanismos de alienação de imóveis da União.

6 Levantamento realizado pela Organização dos Estados Ibero-Americanos para a Educação, Ciência e Cultura (OEI), com o apoio do Ministério da Saúde (https://extra.globo.com/ noticias/brasil/municipios-mais-desmatados-sao-os-mais-violentos-664110.html) 
a participação e governança e implementação de remuneração por serviços ambientais (Programa Bolsa Verde ${ }^{7}$ ).

Os participantes do Seminário O Papel das Áreas Protegidas na Redução das Emissões Oriundas de Desmatamento, reunidos em Brasília em 2009, concluíram que a criação e a gestão eficiente das áreas protegidas em conjunto com os povos indígenas e extrativistas têm um papel crucial para reduzir as emissões de gases do efeito estufa oriundas do desmatamento e da devastação dos ecossistemas e recomendaram que todas as unidades de conservação façam parte de todas as políticas, os projetos e os programas de mecanismos de redução das emissões.

Em consonância com este esforço, em 2012, foi instituída a Política Nacional de Gestão Territorial e Ambiental de Terras Indígenas (PNGATI), com o objetivo de garantir e promover a proteção, a recuperação, a conservação e o uso sustentável dos recursos naturais das terras e territórios indígenas.

\section{MUDANÇA CLIMÁTICA, TRANSFERÊNCIA DE RENDA E CONSERVAÇÃO AMBIENTAL}

Nas últimas décadas do século XX, e sobretudo na primeira década do século XXI, observamos uma crescente discussão sobre direitos sociais e territoriais vinculadas a questões e pautas ambientais, como também uma recorrente discussão sobre a crise ambiental. Segundo Giddens (2010, p. 10), a mudança climática é a dimensão mais urgente e mais grave e profunda da crise ambiental do século XXI, porque aumenta significativamente a desertificação, a crise de recursos hídricos e a crise da biodiversidade, trazendo grandes prejuízos econômicos e afetando severamente as populações pobres do planeta.

A questão territorial e a heterogeneidade sociocultural no Brasil hoje envolvem questões que tratam não somente de ocupação e afirmação territorial, como por exemplo o reconhecimento, demarcação e homologação de terras indígenas, estabelecimentos de unidades de conservação como também a compreensão de políticas sociais e ambientais promovidas por um Estado que tem se pautado pela imposição de uma política socioambientalista que prescreve aos habitantes um dado modo de viver em consonância com princípios conservacionistas.

Estado que de diversas formas tenta transformar estes sujeitos, extrativistas e indígenas em "nativos ecológicos". Segundo Menezes e Bruno (2012, p. 291),

O Programa de Apoio à Conservação Ambiental Bolsa Verde, lançado em setembro de 2011, que concede trimestralmente um benefício de $R \$ 300,00$ ( $R \$ 1.200,00$ por ano) às famílias em situação de extrema pobreza que vivem em áreas consideradas prioritárias para conservação ambiental. 
esta "ecologização" de povos e comunidades tradicionais da Amazônia ou mesmo de caçadores da África Ocidental (LEACH, 2000), sustentam-se em pressupostos românticos que estabelecem um tipo particular de humanidade indissociavelmente ligada à natureza, vivendo em perfeita harmonia com o meio ambiente. A premissa do desenvolvimento sustentável dirigido para as comunidades tradicionais da Amazônia se sustenta nesta percepção da população acima combinada a ações de uma necessária promoção do desenvolvimento econômico amparada na preservação do meio ambiente com base na exploração racional do capital de conhecimentos tradicionais acumulado.

O meio ambiente tornou-se uma gramática cada vez mais frequente para se fazer falar de conflitos sociais (LEITE LOPES, 2004) e despolitizar relações sociais e de poder. Um dos dispositivos desta operação estaria representado no imperativo do conceito de desenvolvimento sustentável, permitindo inscrever o ambientalismo dentro do campo de lutas ideológicas, econômicas e políticas. Neste contexto, habitantes de Terras Indígenas e Unidades de Conservação foram eleitos pelos ambientalistas como a vanguarda ou os bastiões da resistência contra a face mais deletéria do capitalismo: a degradação ambiental, tornandose modelos de uma sociedade alternativa capaz de interagir harmonicamente com o meio ambiente. Assim, coloca-se em marcha um "Processo Civilizatório" (ELIAS, 1993) expresso na imposição de um conjunto de normas que prescrevem uma nova crença e etiqueta expressa em um conjunto de artefatos burocráticos denominados planos de vida, de manejo, de gestão e de uso que de forma supostamente "participativa" vão difundindo determinadas modalidades de sensibilidades ecológicas.

Esta configuração que articula território, conservação e manejo sustentável na Amazônia institucionaliza uma "governança ambiental" que prevê usos racionais da natureza e uma perpétua vigilância (FOUCAULT, 2008) em relação a invasores e vizinhos o que vem alterando um modo consolidado de relacionamento de povos e comunidades tradicionais tais como indígenas, extrativistas e posseiros, que passam a experimentar com cada vez maior frequência conflitos produzidos por visões e agendas institucionais divergentes de entidades governamentais (FUNAI, ICMBIO, INCRA) alicerçadas em valores particulares sobre justiça e desenvolvimento combinados a pressupostos científicos pertinentes a suas áreas de atuação.

Tomamos exemplos coletados em pesquisas realizadas por longo período com moradores da RESEX Médio Purus, situada no município de Lábrea, ao longo do curso médio do rio Purus (Amazonas), inserida na região do arco do desmatamento da Amazônia. A unidade de conservação integra o Programa de 
Áreas Protegidas da Amazônia (ARPA), do governo federal com duração prevista de dez anos, para expandir, consolidar e manter uma parte do Sistema Nacional de Unidades de Conservação (SNUC) no Bioma Amazônia. Observamos as trajetórias dos moradores da Resex Médio Purus que são pautadas na prática atual do extrativismo, da pesca, da agricultura e da criação de pequenos animais. Compartilham de passado recorrentemente relacionado à economia gomífera e madeireira de submissão aos chamados "patrões". Em função da decadência da borracha, tanto extrativistas quanto indígenas que viviam nas diversas comunidades ao longo do médio Purus, buscaram alternativas de sobrevivência, como a coleta de castanha, a plantação de roçados de mandioca para produção de farinha e feijão de praia para consumo e comercialização.

Diante da ênfase dos discursos de analistas ambientais e demais agentes ambientalizados na necessidade de controlar desmatamentos, observamos em muitos casos que a criação de animais e, sobretudo, a abertura de novos roçados pelas famílias, tornaram-se os responsáveis pelo desmatamento na RESEX, segundo os gestores das unidades de conservação, bem como a criminalização da prática das queimadas, prática tradicional agrícola para a abertura de novos roçados. O sistema de roças, tal qual costuma ser desenvolvido por comunidades ribeirinhas, é avaliado como uma prática cultural que deve ser corrigida, pois a tradicional e frequente abertura de novas terras para roçados seria um vetor de desmatamento. As normas sobre gestão de recursos são estabelecidas no processo de discussão do Plano de Utilização, sempre respaldadas na Legislação Ambiental e constituindo o instrumento central para subsidiar a gestão de unidades de conservação. No caso da RESEX Médio Purus, a participação e acordo coletivo sobre as normas estabelecidas no Plano de Utilização foram muitas vezes mencionadas como as precondições para cadastramento e pagamento de serviços ambientais (Bolsa Verde) para as comunidades da RESEX. Se a comunidade não chegasse a um consenso e validasse o plano, incutiam-se incertezas sobre a possibilidade de inclusão dos moradores no programa de transferência de renda denominado Bolsa Verde ${ }^{8}$.

Numa conversa com a consultora que conduziu a elaboração do Plano de Utilização da RESEX Médio Purus, contratada pelo Instituto Chico Mendes para Biodiversidade (ICMBIO), um extrativista tentava explicar para a mesma, durante debate sobre os perigos e as normas corretas para aberturas de roçados

8 Segundo o site do Ministério do Meio Ambiente, "O Bolsa Verde é um programa de transferência de renda para famílias em situação de extrema pobreza que vivem em áreas de relevância para a conservação ambiental. Funciona como um incentivo às comunidades para que continuem usando, de forma sustentável, os territórios onde vivem" Só seriam cadastrados no Programa Bolsa Verde aqueles moradores já cadastrados no Bolsa Família. 
e extrativismo, que sua atividade não causava danos à natureza, pois em sua comunidade os plantios nas várzeas (praias de rio) predominavam em relação aos cultivos de terra firme.

A agricultura, ela não atinge assim um grande impacto, não dá um grande impacto na natureza, na floresta, na RESEX. A gente usa mais as praias... E o extrativismo, quando eu trabalhava era mais com andiroba, copaíba, não muita. A copaíba aqui a gente tem problema pra ver né!" (Extrativista e agricultor da RESEX Médio Purus)

Percebemos que há um "pacote" ambiental previamente estabelecido para ser oferecido e acatado pelas comunidades amazônicas residentes em unidades de conservação naturalmente percebidas como potencialmente predatórias e cujo potencial para a sustentabilidade deve ser induzido por meio de capacitações para a manutenção de condições ambientais ideais. Esta normatização traz consigo a criminalização das formas tradicionais de uso e ocupação do solo e recursos naturais em geral em unidades de conservação. Buscar controlar este modo de relação com o meio ambiente produz um risco para a manutenção da segurança alimentar dos moradores destas áreas. Coibir cultivos como batata-doce, cará, banana pacovã, mandioca e limitar a produção de farinha, determinando-se o tamanho máximo dos roçados ou cerceamento da abertura de novas roças e criação de pequenos animais (galinha e porcos) significa reduzir as possibilidades de manter o modo de vida tradicional que assegura o sustento familiar, tanto no que tange à alimentação, quanto na geração de renda.

\section{HIERARQUIA E CONFRONTO DE SABERES}

O que observamos a partir da forma particular de administração dos roçados da RESEX Médio Purus é que vigora um conhecimento prático, não padronizado, aberto a diferentes protocolos de experimentação (CARNEIRO DA CUNHA; ALMEIDA, 2002). Percebemos a imposição de forma hierárquica e burocrática do um conhecimento científico respaldado pela Lei difundida pelo ICMBio e por organizações não governamentais que buscam multiplicar este modelo de saber. Qualquer espaço de sinergia entre estes saberes costumava ser pouco considerado. $O$ que se presenciou foi o científico-tutelar de um lado e do outro o saber tradicional traduzido pelos primeiros como potencialmente predatório. Segundo Berkes (2009), os cientistas e/ou agentes do Estado não confiam no conhecimento tradicional. E este conhecimento tradicional e oral dificilmente se articula ou se permite acessível ao conhecimento científico. O conhecimento tradicional costuma basear-se em pontos de vista muito diversos 
daqueles da ciência ocidental, bem como partilhar de forma muito reduzida de seu conjunto de códigos. Nos alinhamos com Maturana e Varela (1987) e consideramos que o conhecimento é um comportamento eficaz ou adequado perante um contexto específico, cremos que não deveria haver hierarquia entre saberes tradicionais e científico. Ambos deveriam ser avaliados conforme sua eficácia em dado contexto.

Vale lembrar que fora da macrorregião onde se situa a RESEX Médio Purus reina a flexibilização da legislação ambiental e da fiscalização em relação ao respeito das áreas de Reserva Legal nos empreendimentos agropecuários e madeireiros, ou para a implantação de projetos desenvolvimentistas como hidrelétricas (tal como ocorreu em Santo Antônio e Jirau) ou a repavimentação de estradas (as várias tentativas de recuperação da BR-319/ Porto Velho-Manaus). Portanto, o tratamento é absolutamente desigual em relação à aplicabilidade da lei no que tange ao desmatamento na região, vigorando a flexibilização para os mais poderosos e o rigor da lei para os menos influentes.

De acordo com Taddei (2012, p. 77), na política ambiental, especialmente em países em rápido processo de modernização como o Brasil, a linguagem particular da Ciência e Tecnologia tem sido crucial para os discursos hegemônicos. No entanto, os conhecimentos e as técnicas têm também constituido-se como importantes espaços discursivos para resistir a forças que impedem a continuidade dos modos de vida tradicionais ao impor novas modalidades desenvolvimentistas para a Amazônia. Ao perguntarmos, aos agentes sociais sobre quem agride, destroi ou desmata a floresta, confluíram explicações tais como:

Os madereiros que quebravam seringa entravam em uma área dessa aqui, destruía tanto madeira, como a seringa, que a seringa ela é uma personagem... Ela só não é o Pau Brasil, mas imitando o Pau Brasil (Extrativista da Comunidade Remanso - rio Purus, município de Lábrea)

Eu acredito que o serrador ele destrói mais do que o pescador, porque o pescador ele vive daquilo, mas na hora de ter o peixe proibido na desova, ele para de pescar e não pega aquele tipo de peixe. E os serradores, tendo que serrar pra vender, ele derruba um pau e mata mais de um pau, porque um vai caindo, vai levando os outros, e ali vai acabando com tudo, e às vezes não aproveita nem a madeira como é pra aproveitar... (Extrativista da Comunidade Praia do Santarém - rio Purus, município de Lábrea)

Estas percepções foram bastante recorrentes entre os moradores das comunidades que hoje constituem a RESEX Médio Purus e não são baseadas em fundamentos científicos sobre as causas, os riscos e os efeitos das mudanças climáticas. A maioria destes extrativistas agricultores não tiveram oportunidade 
de escolarização para além da alfabetização ou oportunidade de ter informação específica sobre a centralidade da Amazônia para a regulação do clima planetário, pois nas comunidades só há escolas muito precárias, atualmente, até a quinta série do ensino fundamental.

Nas comunidades não indígenas, as organizações não governamentais não devotam maiores esforços de capacitação. Os esforços concentram-se na capacitação ambiental para populações indígenas caracterizadas por maior alteridade radical. Quando acontecem oficinas nas unidades de conservação, estas são direcionadas para lideranças específicas convocadas pelo ICMbio, em geral extrativistas que de alguma forma já compartilham da crença do imperativo da preservação ambiental e compartilham parcialmente dos códigos científicos.

A produção desta crença se construiu de múltiplas formas, a partir de oportunidades de escolarização, da participação em projetos de viés ambientalista que recrutaram indivíduos da região ou convites para assumir cargos de representação da comunidade que tornou possível a participação frequente em eventos nacionais e internacionais, reforçando a etiqueta ambiental como regulador de conduta e os códigos científicos sobre o funcionamento do bioma amazônico como certezas inexoráveis. Este conjunto de agentes sociais tornaram-se capazes de assumir como porta-vozes e difusores da crença no desenvolvimento sustentável.

Fazer parte da RESEX e ter direito de nela viver é uma resultante da oportunidade que se abriu do ponto de vista legislativo", mas também uma construção social dos moradores a partir de uma releitura de sua saga familiar na região. Há uma memória social de exploração e insegurança territorial que estabelece uma trajetória que relaciona exploração seringalista da qual participaram seus antepassados, continua com o boom da exploração madeireira nos anos 1990 e a transformação da área em unidade de conservação em 2008.

Foi ao longo de processo de luta por segurança territorial, coroado com a criação da RESEX, que foi se produzindo novos significados, percepções e responsabilidades sobre o território que ocupavam. A proteção da floresta, tão preconizada como fundamental para conter as mudanças climáticas, foi primeiramente construída como discurso da chegada do membro da família, e depois de legitimidade e conquista de uma terra histórica e rigidamente controlada pelo poder privado de patrões seringalistas e madeireiros. Uma vez tornada terra coletiva das comunidades, a proteção da floresta impõe-se tanto

9 A RESEX Médio Purus surge como resultado de luta das comunidades e movimento social organizado durante a consulta pública para a criação de Unidades de Conservação na região do entorno da BR (Manaus-Porto Velho)/ Área sob Limitação Administrativa Provisória (ALAP). 
como instrumento de regulação da vida social imposto pelos órgãos ambientais do Estado, por meio de suas ferramentas de gestão, mas também como uma responsabilidade para com aqueles que agora passam à condição de herdeiros da terra, ou seja, filhos, netos, descendentes e partes de uma saga familiar.

Rapaz, é quase bem dizer nós mesmos. A gente não tinha aquele pensar de dizer que essa natureza podia acabar. De certo tempo pra cá, porque eu venho conversando com a comunidade, que o que nós estamos plantando hoje, e o que nós estamos preservando hoje. Vamos supor que não chegue pra nós, vai chegar pros nossos netos, nossos filhos, vamos deixar, e se nós levar como estava antes, acabando com tudo. O que nós ia deixar? Só embaúba, então acredito até que os filhos da gente, os netos, iam dizer assim: poxa o papai dizia que morava aqui tantos anos, e hoje não temos uma árvore pra fazer uma canoa, pra fazer um barraco, porque o nosso pai foi o primeiro a destruir, acabou tudo, deixou só a terra pra nós". Então fica muito difícil. Todo mundo já começou a pensar nisso, eu comecei a conversar com a comunidade, e o povo já começaram realmente a pensar... que eu tava certo, porque eu ia morrer não ia deixar nada, quer dizer que ia morrer, ia morrer a família toda. Porque ninguém ia precisar de nada, mas é diferente, nós temos netos, nós temos filhos, nós temos bisnetos, e tudo vai precisar daquela terra, com certeza precisa da floresta também pra sobreviver como nós precisamos (Extrativista da Comunidade Maciari - rio Purus, município de Lábrea)

A respeito dos relatos acima, Taddei (2012), ao tratar da relação entre cientistas, meteorologistas no Nordeste do Brasil, menciona que os discursos científicos operam com a perspectiva e postura que não são responsáveis pelas implicações ou impactos sobre as informações que eles produzem - é um gênero discursivo abstrato e descontextualizante. Muito diferentes são os discursos dos moradores da RESEX que nomeiam precisamente os agentes sociais responsáveis pela degradação da floresta e, sobretudo, inscrevem o processo de ambientalização coletiva em um processo histórico, personalizado por pessoas e sagas familiares. De forma bastante diversa, esta região é identificada pelos cientistas como parte do "Arco do Desmatamento", ou seja, zona de intervenção prioritária. Em suma, a região é percebida como foco prioritário de políticas públicas de controle de desmatamento, uma lacuna a ser preenchida, um passivo ambiental a ser solucionado até recentemente pelos moradores de Unidades de Conservação e Terras Indígenas por meio de políticas eficazes de gestão territorial.

É importante lembrar que muitas Unidades de Conservação do estado do Amazonas são também beneficiadas pelo pagamento de serviços ambientais por meio do programa de governo do Estado do Amazonas denominado "Bolsa 
Floresta". Segundo estudo de Badr e Mattos (2010), este foi o primeiro programa brasileiro a remunerar, de forma direta, indivíduos pertencentes às comunidades residentes nas florestas pela manutenção dos serviços ambientais, tendo em vista a redução de emissões por desmatamento. O Programa Bolsa Floresta foi criado em 2007 para implementação da política de Mudanças Climáticas, Conservação Ambiental e Desenvolvimento Sustentável do Governo do Estado do Amazonas, consoante o art. 5, II, lei n⿳⺈ 3.135/2007 e tem como objetivo compensar financeira ( $\mathrm{R} \$ 1.360,00$ por família por ano) as comunidades tradicionais que conservam a floresta em pé, assumindo o compromisso do "desmatamento zero", ou melhor, "desmatamento controlado e monitorado".

O programa beneficia os moradores das Unidades de Conservação do estado do Amazonas que comprovem residência em UC estadual há pelo menos dois anos; mantenham áreas de roças com tamanho não superior àquele do ano de instituição do programa, cultivando apenas em áreas de capoeiras abertas ou em descanso e não avançando na mata primária; caso tenham filhos, que estes estejam regularmente matriculados e frequentem a escola e, finalmente, participem da Associação de Moradores da Comunidade e da implementação dos planos de uso e de gestão da Unidade de Conservação, respeitando as suas regras.

A violência simbólica explicitada, sobretudo, na Cartilha do Programa Bolsa Floresta, informa que a família que tiver desmatado área pouco maior que àquela do ano de instituição do Programa Bolsa Floresta (até 50\% a mais) recebe um cartão amarelo e deverá apresentar uma justificativa para a associação, podendo permanecer mais um ano no programa. Em caso de reincidência no desmatamento, recebe-se um cartão vermelho, que resulta na suspensão da concessão do benefício. De acordo com a cartilha, o desmatamento é monitorado anualmente in loco pela equipe da Secretaria do Meio Ambiente e Desenvolvimento Sustentável e por imagens de satélite.

\section{INDÍGENAS E MUDANÇAS CLIMÁTICAS}

Em relação aos grupos indígenas até a década de 1990, o movimento tinha como pauta das suas discussões, demandas e reivindicações, a questão da demarcação e garantia dos seus territórios, bem como o direito a um sistema de saúde e educação que respeitassem suas práticas e costumes. No entanto, a partir do ano 2000 é possível notar que outros elementos foram adicionados à pauta do movimento, uma delas sem dúvida foram "as mudanças climáticas" ${ }^{10}$. É preciso

10 Deve-se mencionar que a chamada PEC-215, proposta que passa a decisão de demarcação das terras indígenas e quilombolas do Executivo para o Legislativo, proíbe a ampliação de terras 
ressaltar que alguns elementos, como desmatamento e conservação dos recursos naturais já eram discutidos anteriormente, mas sem uma relação explícita e direta as alterações do clima.

Esta temática, indubitavelmente, constitui atualmente parte importante das agendas do movimento indígena. No estado do Amazonas, o movimento indígena conjuntamente com organizações não governamentais e o governo do estado tem desenvolvido uma série de discussões, eventos e atividades para discutir e propor ações que minimizem os efeitos e impactos das mudanças no clima. Em 2001, ocorreu o Fórum Indígena Amazônico sobre Mudança Climática, na cidade de Manaus.

Neste evento, que contou com a participação de entidades nacionais, internacionais, científicas e governamentais (Instituto Nacional de Pesquisas da Amazônia (INPA), Instituto de Proteção do Amazonas (IPAAM), IBAMA, GREENPEACE, Fundação Estadual de Política Indigenista (FEPI), Comissão Pastoral da Terra (CPT), CIMI Norte I, Museu Nacional/UFRJ, The Nature Conservancy, Projetos Demonstrativos dos Povos Indígenas (PDPI), Conselho Nacional dos seringueiros (CNS)), foram discutidas as consequências que a mudança climática poderia trazer para os grupos indígenas e agentes sociais que vivem na floresta, na bacia amazônica. No evento, muitas questões ficaram em aberto e o tema ainda era percebido como bastante complexo.

Em 2008, aconteceu o I Seminário - Impactos das Mudanças Climáticas Globais em Manaus e a Bacia do Rio Negro, realizado pelo Instituto Socioambiental (ISA), em parceria com a Secretaria Municipal do Meio Ambiente (SEMMA) e a Secretaria Estadual de Meio Ambiente e Desenvolvimento Sustentável (SDS). Neste evento, duas questões foram discutidas: “a) Que prejuízos o aumento da concentração de gases de efeito estufa na atmosfera pode trazer para a Bacia do Rio Negro, especialmente em Manaus, onde vive a maior parte de sua população? b) Como cada cidadão e os governantes podem se organizar na tentativa de reduzir essas conseqüências negativas?"

Neste, três pesquisadores do Instituto Nacional de Pesquisas da Amazônia (INPA) falaram sobre o tema. O coordenador do Escritório Central do Programa de Larga Escala da Biosfera Atmosfera da Amazônia (LBA, sigla em inglês) falou sobre os "Modelos climáticos e cenários sobre mudanças climáticas para Amazônia"; Um cientista da Coordenação de Pesquisas em Ciências Agronômicas (CPCA) discutiu sobre os "Impactos das mudanças climáticas sobre palmeiras

delimitadas e garante a indenização a fazendeiros. Este atentado aos direitos indígenas cria novos desafios ao movimento e reforça a importância do argumento de que as terras indígenas são fundamentais à estabilidade climática. 
(açaí, pupunha, tucumã, entre outras) de uso econômico"; e um pesquisador da Coordenação de Pesquisas em Biologia Aquática (CPBA), abordou a questão do "Estado atual e futuro dos recursos pesqueiros em Manaus". Notemos que neste evento, havia participação dos indígenas, no entanto estes não eram percebidos como agentes com reflexão própria sobre o tema.

Em 2009, porém observamos que os indígenas foram finalmente colocados nas mesas de discussões e agora os cientistas escutariam suas explicações, visões e conhecimentos sobre o tema. O evento foi realizado em São Gabriel da Cachoeira e foi chamado de "Mudanças Climáticas: Na visão dos Povos indígenas e Cientistas". O mesmo foi realizado pelo ISA em parceria com a FEPI, o Centro Estadual de Mudanças Climáticas (CECLIMA), a SDS e o Governo do Estado do Amazonas.

Ao observamos a organização das mesas e suas composições, sem dúvida houve uma tentativa de diálogo entre os conhecimentos indígenas e o conhecimento científico, mas ainda muito tímido. $\mathrm{O}$ evento ocorreu apenas em um dia e a programação estava organizada da seguinte forma: a) A mesa inicial da primeira parte da manhã era composta por autoridades - governador do estado, na época Eduardo Braga, prefeito de São Gabriel, secretária da SDS, diretorpresidente da FEPI, presidente da FUNAI e representantes da FUNAI local, general da segunda brigada de infantaria de São Gabriel, e coordenadores da Federação das organizações indígenas do Rio Nego (FOIRN) e da COIAB.

A primeira mesa, com o título "Mudanças Climáticas na Visão dos Povos Indígenas e da Comunidade Científica", tinha como moderadora a secretária da SDS e foi composta por três pajés das etnias Dessana, Tuyuca e Baniwa e dois pesquisadores do INPA. Nesta mesa, os pajés discutiram e falaram dos seus conhecimentos e perspectivas do que estava ocorrendo com o clima; $\mathrm{Na}$ segunda mesa que ocorreu no início da tarde intitulada "Mudanças Climáticas em Terras indígenas na visão dos aliados e Parceiros, as instituições (FEPI, ISA, FOIRN, COIAB e COIAM) trataram de discutir suas perspectivas e atividades que pretendiam desenvolver para auxiliar na compreensão do tema. A última mesa intitulada "Mudanças Climáticas e as políticas públicas" foi composta por representantes do CECLIMA, FUNAI, SDS, FEPI e prefeito de São Gabriel que falaram das ações e das atividades de suas instituições para minimizar os efeitos da alteração do clima. Após cada mesa, havia um momento para discussões e debates. Ao final do evento foi lançado o livro "Povos indígenas na gestão pública".

Em 2010 houve também em Manaus - uma primeira consulta pública sobre Princípios e Critérios de Redução de Emissões por Desmatamento e Degradação (REDD). Esta atividade foi uma iniciativa do Grupo de Trabalho 
Amazônico (GTA), do Conselho Nacional de Populações Extrativistas (CNS) e da Coordenação das Organizações Indígenas da Amazônia Brasileira (COIAB). Neste encontro foram realizadas oficinas para capacitar lideranças dos povos da floresta, incluindo índios, seringueiros, ribeirinhos para compreender e entender mais sobre a relação entre mudanças climáticas e REDD. Ainda entre 2010 e 2011, a COIAB com apoio da The Nature Conservancy, do Instituto de Pesquisa Ambiental da Amazônia (IPAM) e da Embaixada da Noruega realizou um curso de formação e capacitação desenvolvido pelo Centro Amazônico de Formação Indígena (CAFI) que resultou na publicação da Cartilha "Mudanças climáticas e aquecimento global na visão dos povos indígenas".

A cartilha foi elaborada durante o curso e tem como autores indígenas de diversas etnias não só do Amazonas, mas também de outros estados brasileiros. Ela está estruturada em quatro capítulos que tratam dos seguintes temas: I- O clima antes e hoje; II- O aquecimento da terra e as mudanças do meio ambiente; III- Propostas e ações para a redução do aquecimento da terra; e IV - Preparo para a participação dos povos indígenas nas ações de combate às mudanças climáticas e ao aquecimento da Terra. Este último capítulo é voltado para discussão sobre REDD (regulamentação, políticas nacionais e internacionais, marcos legais, entre outras questões). No material temos uma combinação de conceitos técnicos científicos, desenhos e explicações indígenas.

Embora a temática venha sendo discutida há mais de dez anos no estado do Amazonas, observamos que não existe um esforço significativo por parte da comunidade científica em estimular e de fato compreender como estes fenômenos são percebidos e explicados pelos indígenas: O que de fato percebem, o que está mudando, como eles explicam, como eles se apropriam desses conceitos e os reinterpretam.

Conforme assinala Taddei (2012, p. 91), para garantir que suas explicações não sejam folclorizadas, romantizadas, antimodernas, muitos indígenas para participar efetivamente da construção desse conhecimento, sobretudo, sobre REDD tem adotado formas tecno-científicas de compreensão e expressão sobre o ambiente natural o que muitas vezes significa abrir mão das suas visões de mundo específicas. Posey (2001, p. 86), ao discutir a interpretação e utilização dos conhecimentos nativos pela ciência, esclarece que áreas como, por exemplo, a etnobiologia tende a considerar o conhecimento nativo somente em relação ao que é previamente conhecido pela ciência.

Assim, investigam-se somente categorias de uso de plantas, comportamentos animais, relações ecológicas, tipos de solo e paisagens que estejam abordados no próprio sistema de conhecimento científico. As 
proposições de hipóteses inspiradas no conhecimento indígena são submetidas a uma etapa prévia de purificação (LATOUR, 2004) onde precisam ser excluídos os elementos improváveis e inacreditáveis presentes nos relatos dos informantes, o que, segundo Posey indica que "improvável" e "inacreditável" seria a inabilidade dos pesquisadores de reconhecer a "realidade" indígena de qualquer critério científico real. Um exemplo desta postura pode ser observada, no material organizado pelo Instituto Socioambiental intitulado "Manejo do mundo: conhecimentos e práticas dos povos indígenas do rio Negro - Noroeste Amazônico (CALBAZAR, 2010), que faz uma tentativa de cruzar perspectivas e conhecimentos indígenas e científicos sobre o tema.

Aqui destacaremos um texto do capítulo "Ciclos de vida e mudanças climáticas", denominado "Floresta e clima: saber indígena e ciência", escrito por um pesquisador do INPE. Neste texto, o autor fala de sua experiência com os indígenas quando participou do evento Fórum Indígena Amazônico sobre Mudança Climática' (mencionado acima) e buscou apresentar o conhecimento científico sobre o papel da floresta (fotossíntese, sequestro de carbono, entre outras questões) nas mudanças climáticas para uma plateia sem treinamento científico. (2010, p. 38). Segundo o mesmo, após ser duramente criticado pela plateia, expos e ressaltou que mesmo que o conhecimento indígena fosse reconbecido por poucos no universo científico, o diálogo entre os dois tipos de saberes era extremamente necessário. Assim, alinhavando narrativas Yanomami e explicações científicas, o mesmo vai "traduzindo" e explicando como a floresta interfere nas alterações do clima, mas utilizando o conhecimento Yanomami apenas quando estava em conformidade com as explicações da ciência.

Em 5 de junho de 2012, Dia Mundial do Meio Ambiente, a Presidência da República institui a Política Nacional de Gestão Territorial e Ambiental de Terras Indígenas ${ }^{11}$ (PNGATI) que teve como eixos: a proteção territorial e dos recursos naturais e a governança e participação indígena em processos relacionados à gestão de suas terras, prevenção e recuperação de danos ambientais em TI, uso sustentável de recursos naturais e fortalecimento de iniciativas produtivas indígenas. São definidas como ferramentas para a gestão territorial e ambiental de terras indígenas o etnomapeamento e o etnozoneamento e, desde a instituição do PNGATI houve uma corrida destas ações de mapeamento participativo em Terras Indígenas voltados a registrar, localizar e diagnosticar participativamente todas as áreas de relevância ambiental, sociocultural e produtiva existentes.

O Fundo Amazônia administrado pelo Banco Nacional de Desenvolvimento Econômico e Social (BNDES) aprovou o investimento de

${ }_{11}$ Decreto $^{\circ}$ 7.747/2012 (DECRETO DO EXECUTIVO), de 06 de maio de 2012. 
$\mathrm{R} \$ 16,4$ milhões para o estado do Amazonas para desenvolver um projeto de gestão ambiental sustentável das Terras Indígenas. O programa, com prazo de 36 meses, abrange cerca de 50\% dos territórios indígenas do estado (16,2 milhões de hectares) e atinge uma população de 35 mil índios. O objetivo é reduzir as atividades exploratórias que levam à degradação dos recursos naturais com investimentos no monitoramento da região e fortalecimento institucional das associações. As TI detêm um dos menores índices de desmatamento entre as diversas categorias de áreas protegidas. No entanto, sofrem pressão sobre seus recursos naturais, especialmente em áreas limítrofes com estradas e rios de maior circulação. Dentre vários objetivos, o projeto prevê a implantação de planos de gestão ambiental e bases de monitoramento.

Tanto no caso das Unidades de Conservação como da Terras Indígenas, percebemos como recorrentemente há o controle sobre modos de vida tradicionais com a imposição de um novo conjunto de crenças e normas que estabelecem um processo civilizador mediado pela difusão de uma nova etiqueta de regulação do mundo social indígena e extrativista amazônicos, acompanhados da crescente responsabilização de povos e comunidades tradicionais pelo monitoramento e controle do desmatamento, meta da Política Nacional de Mudança do Clima. As razões para a aceitabilidade da nova condição costumam ter explicações diversas, seja a crença num ônus pela conquista da terra ou mesmo por uma associação entre dominação do patrão e dominação do Estado, entidades que se revezariam mediando e fazendo exigências para permitir o direito ao uso da terra. Historicamente, vemos se reatualizar a função antes atribuída aos indígenas de estabilizar e demarcar as fronteiras nacionais, agora reeditada para a manutenção, gestão e vigilância das fronteiras da conservação ambiental na Amazônia.

\section{REGULARIZACÃO FUNDIÁRIA: INFLEXÃO E O NOVO PAPEL DA AMAZÔNIA NO CENÁRIO AMBIENTAL}

A partir de 2009, observa-se uma inflexão em termos de políticas públicas para o desenvolvimento da Amazônia, percebe-se uma progressiva ação de investimento na autogestão territorial e desenvolvimento sustentável de povos indígenas e comunidades tradicionais para uma reorientação para a regularização territorial de terras não destinadas. O Programa Terra Legal seria o grande divisor em termos de mudança de ênfase, com o objetivo de promover a regularização fundiária de ocupações baseadas em posses mansas e pacíficas dentro de terras federais na Amazônia Legal. 
Este programa se fundamenta na no Lei 11.952, sancionada pelo expresidente Lula, em 2009. As glebas federais na Amazônia compreendem uma área que equivale a mais de um quarto do território amazônico, tendo certificado cerca de 69 milhões de hectares que permitiram a destinação das terras. A primeira forma é a destinação para fins públicos e coletivos, como terras indígenas, unidades de conservação e assentamentos da reforma agrária, usos que se sobrepõem aos privados. No início de 2016 o programa contava com mais 18 mil títulos emitidos nas áreas públicas federais, conduzindo a emissão de mais de seis mil títulos em áreas públicas estaduais.

O Programa Terra Legal constitui-se um ambicioso e ousado programa de regularização fundiária do país, visando regularizar cerca 67 milhões de hectares de terras, cerca de 8\% do território nacional. Criado em 2009 pelo Ministério do Desenvolvimento Agrário, tinha como meta dar segurança jurídica aos produtores rurais da Amazônia Legal e reforçar as políticas públicas de preservação do meio ambiente na região. Desta forma, o Programa foi descrito pelo então ministro extraordinário de Assuntos Estratégicos e coordenador do Plano Amazônia Sustentável (PAS), Mangabeira Unger, da seguinte forma: "Sem tirar a Amazônia da situação de insegurança jurídica em que se encontra, ninguém sabe quem tem o quê. Não avançaremos em nada mais.”

Em 2008, a Secretaria de Assuntos Estratégicos (SAE) da Presidência da República e o International Bank for Reconstruction and Development (BIRD) realizaram, em Brasília, o Seminário Internacional "O Desafio da Regularização Fundiária na Amazônia", que subsidiou a negociação do governo federal com os nove governadores da Amazônia Legal sobre a regularização fundiária na região. As condições convergiam para constituir a regularização fundiária como problema número um da Amazônia brasileira.

Coadunando-se com o cenário de aumento de crescimento da produção de commodities na região, o processo de destinação das terras públicas da União para a administração dos governos estaduais da Amazônia Legal foi tornando imperativo o processo de aceleração de legalização das terras públicas, por meio do repasse de recursos com a finalidade fortalecer os institutos estaduais de terras e dar a estas terras uma destinação.

Constrói-se desta forma o volume de terras a regularizar pelo Programa Terra Legal, que após inúmeras denúncias de irregularidades, sofreu uma auditoria sistematizada no Relatório de Fiscalização do Programa Terra legal, realizado pelo Tribunal de Contas da União $(2014,14)$ baseado na consulta nos dados disponibilizados no Sisterleg (Base de Dados do Sistema Terra Legal). O Programa concluiu até meados de 2014, 7.951 processos de titulação dos quais 
5.607 de áreas abaixo de um módulo fiscal (MF) totalizando 174.577 ha; 2056 processos de 1 a 4 MF totalizando a titulação de 263.429 ha e 292 processos acima de quatro MF, somando 170.947 ha titulados.

Os estados com mais títulos acima de quatro módulos fiscais situavam-se nas áreas de maior expansão da fronteira agropecuária, ou seja, Pará, Mato Grosso, Tocantins e Maranhão. Foi orçado um total de $\mathrm{R} \$ 324,5$ milhões e para atender a meta de titulações (150 mil beneficiários) entre 2011 e 2014. Mantendo-se o ritmo detectado pelo TCU seriam necessárias mais quatro décadas para se atingir as metas propostas. Em 2005, esta lei que criou o Programa Terra Legal sofreu importantes modificações no sentido de estender os limites de regularização, ampliando para 500 hectares, e, posteriormente, por meio de medidas provisórias tornadas lei, o limite estendido a 15 módulos fiscais (na Amazônia cada módulo mede 76 hectares), ou não ultrapassando 1.500 hectares, dimensão impossível de ser enquadrada como pequena propriedade familiar.

No caso da Amazônia, o efeito dessas mudanças se expressaria na disponibilização de 67,4 milhões de hectares de terras da União em condições de incorporação ao mercado de terras (12\% da região amazônica), montante reduzido a 58,8 milhões após consulta a órgãos que alegaram destinação definida de parte desta área para unidades de conservação, terras indígenas e assentamentos rurais. O saldo de terras a regularizar seria ainda maior se levada em conta, segundo dados do Ministério do Desenvolvimento Agrário (MDA), a existência de mais de 100 milhões de hectares de terra na Amazônia sob controle dos estados e gestão dos Institutos de Terras e também passíveis de regularização.

As frustrações com "lentidão no processo de regularização fundiária" na Amazônia constituíram bases para a criação do Grupo Executivo Intergovernamental para a Regularização Fundiária na Amazônia Legal (GEI). O GEI surgiu como um movimento sincronizado, catalizador de ações, a fim de definir diretrizes para acelerar o processo de destinação de terras públicas na Amazônia, nos quais se destacam as seguintes representações governamentais: Casa Civil da Presidência da República, Secretaria de Assuntos Estratégicos da Presidência da República, Ministério do Desenvolvimento Agrário, Ministério do Meio Ambiente, Ministério do Planejamento, Orçamento e Gestão e Instituto Nacional de Colonização e Reforma Agrária. A fim de acelerar a regularização fundiária, compreendeu-se a necessidade de aceitar nas reuniões do Grupo Executivo Intergovernamental, os governadores dos estados e outros órgãos e entidades da administração pública, por exemplo, coordenadores estaduais do Programa Terra Legal Amazônia. 
Durante as reuniões do GEI acordou-se sobre a flexibilização dos documentos comprobatórios necessários para regularização fundiária, resultando na simplificação e agilidade nos pareceres favoráveis à expedição de títulos definitivos. Detectaram-se assim os gargalos que "burocratizavam" a expedição de títulos definitivos, não só em termos de documentos mínimos necessários para andamento dos requerimentos de regularização fundiária, como na discussão de flexibilização de outras leis e normativas relacionadas à Lei no 11.952 .

Em 2014, ainda durante o governo Dilma Roussef, o GEI passou a adotar providências de simplificação do processo de regularização fundiária: medidas administrativas de impacto para agilizar os processos e aumento de títulos definitivos sob supervisão da Cooperação Técnica Alemã (GIZ). Aumentou o tamanho dos lotes de reforma agrária de 1 módulo fiscal para 2, e atendeu reivindicações para regularização fundiária de imóveis rurais acima de 15 módulos fiscais. Outra reivindicação era a renegociação das dívidas dos títulos antigos e a possibilidade de legalização dos processos indeferidos devido à prática de grilagem como ocorreu no sul de Lábrea (AM).

Aventamos como hipótese que as mudanças introduzidas pela chamada Medida Provisória 759 convertida em atualmente em Lei no 13464/2017 estariam em consonância como o trabalho desenvolvido pelo Programa Terra Legal, especialmente quanto ao seu aspecto desburocratizante. Em entrevista com os técnicos do Programa Terra Legal, descobriu-se que a MP respondia muitas demandas apresentadas no GEI, entre as causas alegadas a possibilidade de aumentar significativamente a legalização de terras. Pode-se concluir que a chamada MP 759 é um desfecho deste movimento iniciado em 2009 e uma resultante dos acordos estabelecidos no âmbito do GEI visando criar uma "Terra Legal sem burocracia".

Em meados de 2017, com a sanção pelo presidente da República da Medida Provisória 759/2016, produziu-se a atualização da Lei do Programa Terra Legal n⿳0 11.952/2009 e estabelecidas novas regras para a regularização de terras da União ocupadas na Amazônia Legal por meio do agora denominado Programa Nacional de Regularização Fundiária. Este novo marco legal objetiva promover o desenvolvimento da política de regularização fundiária em todo país.

Deve-se salientar que o Programa Terra Legal apresentava-se como uma política voltada para a segurança jurídica dos produtores rurais da Amazônia Legal e ao reforço das políticas públicas de preservação do meio ambiente na região. As mudanças no Código Florestal se coadunam com estas metas e traz 
como instrumento o Cadastro Ambiental Rural (CAR ${ }^{12}$ ) integrado ao SICAR, no qual deverá apresentar os dados ambientais de sua propriedade rural no Estado. O produtor rural que não se inscrever no CAR torna-se irregular, com impedimentos de licenciamento ambiental, financiamentos e obstáculos para a comercialização de sua produção.

Por pressão das organizações não governamentais por transparência total, os dados do CAR foram tornados públicos no final de 2016. A Confederação da Agricultura e Pecuária do Brasil (CNA) protocolou na Procuradoria-Geral da República, representação contra o ministro do Meio Ambiente, Sarney Filho por crime de responsabilidade e improbidade administrativa, ao determinar a divulgação pública, pela internet, de dados sigilosos do produtor rural contidos no Cadastro Ambiental Rural (CAR). Alguns dias depois o ministério retrocedeu e retirou da internet o nome das propriedades rurais.

Se anteriormente muitas $\mathrm{ONG}$ de perfil ambientalista se posicionavam favoráveis ao veto das mudanças no Código Florestal, atualmente estas se colocam como fiscalizadoras dos compromissos assumidos pelos produtores rurais apoiando assim o aperfeiçoamento da base técnica do CAR. De forma pejorativa, muitos produtores incomodados com a vigilância das ONG as denominam de "lobistas do CAR"13.

A análise do que vem sendo divulgado na imprensa, possivelmente por setores ruralistas, sobre a relação entre ONG e CAR é bastante intrigante, visto que reforça a ideia de que as ONG doutrinam a imprensa (A Conservation International é citada como exemplo) sobre a importância do CAR para a regularização dos imóveis rurais no Brasil e sobre a importância deste instrumento para o alcance do desmatamento ilegal zero. É sempre lembrado que as ONG se opuseram à reforma do Código Florestal por meio de seminários para jornalistas reforçando que o novo Código Florestal é um retrocesso e deveria ser vetado ${ }^{14}$.

Para os produtores o risco da divulgação pública do CAR não estaria na área a ser preservada nos imóveis rurais em Áreas de Preservação Permanente ou Reserva legal, mas nos passivos ambientais, ou melhor, na área que cabe a cada propriedade recuperar de vegetação nativa nos anos futuros. O passivo

12 O Cadastro Ambiental Rural foi criado para monitoramento, preservação e recuperação de florestas em propriedades privadas, espaços onde mais se detecta o avanço do desmatamento.

13 No encontro para a divulgação do CAR, realizado pelo ministro do Meio Ambiente estavam representantes do ISA, BVRio, IPAM, WWF, SOS Mata Atlântica, The Nature Conservancy, Friends of the Earth. Disponível em: https://www.noticiasagricolas.com.br/noticias/ meio-ambiente/183884-divulgacao-do-car-foi-acertada-com-ongs-em-outubro.html\#. WpOPNLpFxy1 Acesso em: 24 fev. 2018

14 Disponível em: http://www.codigoflorestal.com/2016/03/ongs-promovem-seminario-para. html Acesso em: 24 fev. 2018 
ambiental seria o verdadeiro interesse e motivador do controle e ação das ONG. Cabe ressaltar que a ONG The Nature Conservancy (TNC) costuma destacar sua experiência acumulada ao longo de quase uma década e está na disputa pelo cadastramento de imóveis rurais que exige habilidades em informática e conhecimento cartográfico. A representante da TNC no Brasil informou que a organização foi a primeira a implantar o CAR em grande escala no país. O projeto da TNC tem como foco os municípios que formam o arco do desmatamento na Amazônia.

\section{CONSIDERAÇÕES FINAIS}

$\mathrm{Na}$ primeira parte deste texto buscamos destacar como indígenas e comunidades tradicionais habitando áreas florestais mais preservadas e por esta razão constituíram focos para ações de promoção do desenvolvimento sustentável de agências estatais e ONG que se empenhavam no controle de desmatamento por meio do monitoramento do crescimento dos roçados, no controle da pesca predatória nos lagos e por meio do apoio destas atividades com pagamento por serviços ambientais como mecanismo de compensação para que se reduzisse a pressão sobre os recursos naturais. Destacamos ainda a dificuldade de se produzir uma sinergia entre conhecimentos científicos que frequentemente traduziam de modo folclorizado ou romantizado os conhecimentos tradicionais.

A recente e drástica mudança no marco legal da regularização ambiental e fundiária sinaliza que um estoque importante de terras formais serão disponibilizadas ao mercado para a produção rural, fechando ou dificultando muito novas possibilidades para expansão e criação de territórios indígenas e para comunidades tradicionais. Vale lembrar que as mesmas ONG que realizavam etnomapeamentos colaboram para o Cadastro Ambiental Rural e outras se empenharão nos projetos de controle e monitoramento do desmatamento e passivo ambiental em áreas cadastradas ou tituladas.

Finalmente, conforme buscamos demonstrar, houve uma mudança no eixo e objeto de debate das mudanças climáticas na Amazônia na última década. Ainda que o tema ainda esteja focado no desmatamento, os meios mudaram. Os projetos direcionados para a agricultura de baixa emissão de carbono com práticas agrícolas sustentáveis que integrem lavoura-pecuária e floresta ganham força como estratégia de combate à crise climática ${ }^{15}$. Houve mudanças nas estratégias para reduzir o desmatamento e novos grupos sociais se tornaram protagonistas deste processo.

15 O relatório completo deste estudo está dispOnível o www.Observatorioabc.com.br. 
Desde 2009 com o Programa Terra Legal e mais recentemente com a aprovação da MP 759 e a reforma do Código Florestal, os segmentos ruralistas tem alcançado vitórias importantes com estas mudanças do marco legal, transformações retoricamente dirigidas ao combate do fundiário amazônico, a segurança territorial dos produtores rurais gerando a formalização de um imenso mercado de terras. As mudanças sinalizam a nova prioridade do destino das terras públicas amazônicas: o desenvolvimento agropecuário.

O novo rumo na política territorial significa a retirada do protagonismo de indígenas e povos tradicionais do front do combate das mudanças climáticas. As ONG repercutiram esta inflexão e estão agora "de olho nos ruralistas" seja, focando suas ações no controle de ações chamadas de "integracionistas" expressas no arrendamento de suas terras para o agronegócio, por exemplo. O Ministério da Agricultura, Pecuária e Abastecimento (MAPA) em audiência no final de dezembro de 2016, no Senado afirmou que os índios "não podem ficar à margem da tecnologia e têm que ser integrados". O cenário se agrava e facilita investimentos integracionistas diante da drástica redução de recursos para a FUNAI, que teve o maior corte de recursos da última década.

\section{REFERÊNCIAS}

AB'SABER, Aziz Nacib. Entrevista concedida para a revista National Geographics, de setembro de 2007. Disponível em: < https://opiniaosocialista. wordpress.com/textos-fundamentais/aquecimento-global-opiniao-de-aziznacib-ab $\%$ C2\%B4saber/>. Acesso em 24 fev. 2018

\section{ALUNOS INDÍGENAS, Cartilha mudanças climáticas e aquecimento} global na visão dos povos indígena. Manaus: COIAB/CAFI, 2011

BARD, F; MATTOS, F. Remuneração pela preservação da floresta em pé análise do REDD e a experiência do programa Bolsa Floresta do Estado do Amazonas. In: ENCONTRO NACIONAL DO COMPEDI, 19. Fortaleza, 2010. Anais... Fortaleza, 2010

BERKES, Fickret. Evolution of co-management: Role of knowledge generation, bridging organizations and social learning. Journal of Environmental Management, n. 90, p. 1692-1702, 2009.

BOURDIEU, P. Language and symbolic power. Cambridge, MA: Harvard University Press, 1991.

16 Parafraseando o site De olho nos ruralilstas: observatório do agronegócio no Brasil (https:// deolhonosruralistas.com.br/) 
BRUNO, Ana C; MENEZES, Thereza C. C. Quando os discursos sobre mudanças climáticas modificam as agendas e afetam a vida dos sujeitos sociais - indígenas e extrativistas. In: REUNIÃO BRASILEIRA DE ANTROPOLOGIA (RBA), 29. - Diálogos Antropológicos expandindo fronteiras. Natal, 2014 Anais... Brasilia: Kiron, 2014. p. 01-12.

CALBAZAR, Aloisio (Org.). Manejo do mundo: conhecimentos e práticas dos povos indígenas do Rio Negro - Noroeste Amazônico. São Paulo, ISA: São Gabriel da Cachoeira-AM: FOIRN. 2010.

CARNEIRO DA CUNHA, Manuela; ALMEIDA, Mauro B. (Org.). A enciclopédia da Floresta. São Paulo: Companhia das Letras, 2002

CORREIO BRASILIENSE. Brasília, 20 fev. 2007.

ELIAS, Nobert. O processo civilizador: formação do Estado e civilização. Rio de Janeiro: Jorge Zahar, 1993.

FEARNSIDE, P.M. "La vulnerabilidad de la selva amazónica frente a los cambios climáticos", em PENICHE CAMPS, F. González , E. Macías Franco, M. Guzmán Arroyo \& G. Zavala García (eds.) II Seminario Internacional sobre la Cuenca del Río Santiago: El Cambio Climático. Centro Universitario de Ciencias Económico-Administrativos (CUCEA), Universidad de Guadalajara, Guadalajara, Jalisco, México, 15-31. 2012.

FOUCAULT, Michel. Segurança, território, população. Rio de Janeiro: Martins Fontes, 2008.

GIDDENS, Anthony. A política da mudança climática. Rio de Janeiro: Zahar, 2010.

IPCC - Intergovernmental Panel on Climate Change. Climate Change 2007: Mitigation. Contribution of Working Groups III to the Fourth Assessment Report of the Intergovernmental Panel on Climate Change. Cambridge: Cambridge University Press, 2007.

LATOUR, Bruno. Jamais fomos modernos. São Paulo: Editora 34, 2004.

LEACH, M. New shapes to shift: war, parks and the hunting person in modern west Africa. Man, v. 6, n. 4. 2000

LEITE LOPES, J. S (Coord.). A ambientalização dos conflitos sociais. Rio de Janeiro: Relume Drumará, 2004. 
MATURANA, H. R.; VARELA, F. J. The tree of knowledge: the biological roots of human understanding. Boston: Shambhala. 1987.

MENEZES, Thereza; BRUNO, Ana Carla. A floresta e sociedade: tradição e cultura. In: HIGUCHI, M. I. G.; HIGUCHI, Niro (Ed.). A floresta e suas múltiplas dimensões: uma proposta de educação ambiental. 2. ed. rev. e amp. Manaus: INPA/CNPq, 2012. p. 287-308

MENEZES, Thereza. Dois destinos para o Purus: Desenvolvimento, socioambientalismo e emergência dos povos tradicionais no Sul do Amazonas. In: MENDES DOS SANTOS, G. Álbum Purus. Manaus: EDUA, 2011.

Nature 481(7381):321-8 · January 2012. The Amazon Basin in Trasition. Disponível em: <https://www.researchgate.net/publication/221760309_The_ Amazon_Basin_in_transition> Acesso em 09 mar.2018

NOBRE, Antonio Donato. "Floresta e Clima. Saber Indígena e Ciência", em Manejo do Mundo: Conhecimentos e Práticas dos Povos Indígenas do Rio Negro - Noroeste Amazônico. São Paulo, ISA: São Gabriel da Cachoeira-AM: FOIRN. 2010.

POSEY, Darrel. Interpretando e utilizando a realidade dos conceitos indígenas: o que é preciso aprender dos nativos? In: DIEGUES, Antônio Carlos S. e Moreira, André de Castro C. Espaços e recursos naturais de uso comum. São Paulo, Nupaub. 2001. p. 279-294

RELATÓRIO DE AUDITORIA DE CONFORMIDADE NO PROGRAMA TERRA LEGAL AMAZONIA. TCU, 2014. Disponível em: <http:// pt.slideshare.net/fullscreen/SindPFA/relatrio-de-fiscalizao-do-programa-terralegal-pelo-tcu-2014/3>. Acesso em: 24 fev.2018

SOARES FILHO et al. Redução das emissões de carbono por desmatamento no Brasil: o papel do Programa Áreas Protegidas da Amazônia (ARPA). Relatório técnico IPAM e WWF. 2009.

SUMÁRIO/RIO EXECUTIVO: Agricultura de baixa emissão de carbono: financiando a transição. Análise dos recursos ABC. Observatório ABC. Disponível em: www.observatorioabc.com.br. Acesso em: 24 fev.2018

TADDEI, Renzo. Social Participation and the politics of climate in Northeast Brazil. In: LATTA, Alex and Hannah WITTMAN, (Ed.), Environment and Citizenship in Latin America: Natures, Subjects and Struggles. New York, Berghahn Books. 2012. p. 77-94 
Of clouds and streams, prophets and profits: the political semiotics of climate and water in the Brazilian Northeast. 2005. PhD dissertation, Graduate School of Arts and Sciences, Columbia University, New York. 2005. 